\title{
Effects of Vitamin D Supplementation on General and Central Obesity: Results from 20 Randomized Controlled Trials Involving Apparently Healthy Populations
}

\author{
Leizhen Duan ${ }^{\mathrm{a}}$ Ling Han ${ }^{\mathrm{a}}$ Qin Liu ${ }^{\mathrm{a}}$ Yili Zhao $^{\mathrm{a}}$ Lei Wang ${ }^{\mathrm{a}}$ Yan Wang ${ }^{\mathrm{b}}$ \\ a Department of Medical Services, Zhengzhou Central Hospital affiliated to Zhengzhou University, Zhengzhou, \\ China; ${ }^{b}$ Public Health and Preventive Medicine Teaching and Research Center, Henan University of Chinese \\ Medicine, Zhengzhou, China
}

\section{Keywords}

Vitamin D - Obesity - Body mass index - Waist circumference . Waist-to-hip ratio

\begin{abstract}
Background: The obesity pandemic has been paralleled by a high prevalence of vitamin D deficiency (VDD). There is growing epidemiological evidence linking low vitamin D status with obesity events. In addition, observational studies also show that obesity may increase the risk of VDD. However, there is insufficient knowledge to understand whether there is a causality between the two. Moreover, the impact of vitamin $D$ supplementation on obesity indices has shown inconsistent outcomes. Objective: This meta-analysis aimed to assess whether vitamin D supplementation modified general and central obesity indices in apparently healthy populations. Methods: A systematic retrieval of relevant randomized controlled trials (RCTs) was undertaken using Pubmed, Embase, Web of Knowledge and Chinese National Knowledge Infrastructure databases. The pooled weighted mean difference (WMD) and 95\% confidence intervals $(\mathrm{Cl})$ were used to assess the changes in body mass index (BMI), waist circumference (WC), waist-to-hip ratio (WHR) and 25-hy-
\end{abstract}

droxyvitamin D (25[OH]D) from baseline. Results: Twenty RCTs involving 3,153 participants reporting either BMI, WC, WHR or 25(OH)D met the inclusion criteria. When compared with placebo, vitamin $\mathrm{D}$ supplementation had no significant decreases in BMI (WMD $=-0.09 \mathrm{~kg} / \mathrm{m}^{2}, 95 \% \mathrm{Cl}-0.19$ to 0.01 , $p=0.08$ ), WC (WMD $=-0.71 \mathrm{~cm}, 95 \% \mathrm{Cl}-1.58$ to $0.16, p=$ 0.112 ) or $\mathrm{WHR}$ (WMD $=0.00,95 \% \mathrm{Cl}-0.01$ to $0.01, p=0.749$ ). However, in the subgroups of females, Asia region studies and intervention duration $\geq 6$ months, a beneficial and significant reduction in BMI and WC was noted (all $p<0.026$ ). On the other hand, pooled results showed that there was a significant increase in serum 25(OH)D levels (WMD $=13.20$ $\mathrm{ng} / \mathrm{mL}, 95 \% \mathrm{Cl} 9.83-16.58, p<0.001)$ after vitamin $\mathrm{D}$ intervention. No publication bias was found in our study. Conclusions: Overall, supplementation with vitamin D produced no significant effect on the BMI, WC or WHR of healthy adults.

(c) 2020 S. Karger AG, Basel

\section{Introduction}

Obesity is defined as an abnormal or excessive accumulation of body fat resulting from an imbalance between energy intake and expenditure. The obesity epi- 
demic affected an estimated 650 million adults and 124 million children in 2016 [1], and this condition increases the risk of chronic diseases like diabetes, cardiovascular diseases and cancer [2]. Currently, it is considered to be the fifth greatest risk factor for mortality [1]. A low serum vitamin $\mathrm{D}$ level is one of the metabolic disturbances associated with obesity [3]. The serum levels of 25-hydroxyvitamin $\mathrm{D}(25[\mathrm{OH}] \mathrm{D})$ are commonly used as a biomarker for the long-term vitamin D nutritional status of an individual [4]. The Institute of Medicine defines vitamin D deficiency (VDD) as a medical outcome characterized by rickets and osteomalacia, with a serum $25(\mathrm{OH}) \mathrm{D}$ concentration $<20 \mathrm{ng} / \mathrm{mL}(50 \mathrm{nmol} / \mathrm{L})$ [5]. Currently, both obesity and VDD constitute worldwide epidemiological problems.

Obesity and VDD often coexist. Body mass index (BMI) and abdominal fat mass are known determinants of vitamin D status, and VDD is common in individuals with obesity [6]. Observational studies from a recent meta-analysis showed an inverse relationship between $25(\mathrm{OH}) \mathrm{D}$ levels and BMI both in diabetic and nondiabetic groups [7]. The first meta-analysis quantifying the association between obesity and VDD showed that the prevalence of VDD was 35\% higher in the obesity group than in the control group [8]. However, it is still unclear whether VDD is a cause or an outcome of obesity. One proposed theory posits that vitamin $\mathrm{D}$, being fat soluble, can be sequestered in cutaneous and visceral adiposity depots, resulting in low serum vitamin $\mathrm{D}$ levels in obese individuals [9]. An alternative theory proposes that volumetric dilution can explain most of the differences in serum $25(\mathrm{OH}) \mathrm{D}$ levels between obese and lean individuals [10]. Different mechanisms may explain why VDD is associated with a higher risk of adiposity. On the one hand, VDD increases parathyroid hormone levels and promotes a greater inflow of calcium $(\mathrm{Ca})$ into adipocytes [11]. On the other hand, VDD might accelerate the differentiation of preadipocytes into adipocytes [12]. Both conditions could influence the obesity risk either directly (e.g., by increasing adipogenesis) or indirectly (by modulating inflammation, oxidative stress, metabolism and gene regulation) [13]. A study on diet-induced obesity in a mouse model showed that a high vitamin $\mathrm{D}$ and $\mathrm{Ca}$ intake can activate the $\mathrm{Ca}^{2+}$-mediated apoptotic pathway in adipose tissue, which would alleviate obesity by reducing body fat [14]. In addition, the vitamin D receptor and the vitamin D-metabolizing enzymes which produce $25(\mathrm{OH})$ $\mathrm{D}$ and $1,25(\mathrm{OH})_{2} \mathrm{D}$ are expressed in human adipose tissue, strongly suggesting there is a complex relationship between vitamin $\mathrm{D}$ and obesity $[13,15]$.
Two patterns of obesity, general (peripheral) obesity and central (abdominal) obesity, are often involved in epidemiological anthropometry. The BMI is one of the most commonly used anthropometric indices to determine the presence of general obesity in clinical practice and in population surveys [16]. Most observational studies have confirmed that vitamin D status is inversely correlated with the BMI [7]. However, several randomized controlled trials (RCTs) and a recent meta-analysis on the effects of vitamin D supplementation on BMI did not seem to support this correlation [17-20]. On the other hand, several studies have suggested that central obesity is considered as a better predictor of several adverse health outcomes and mortality $[21,22]$. Thus, more attention should be paid to the current prevalence of central obesity. Waist circumference (WC) and waist-to-hip ratio (WHR) are ideal indicators for evaluating central obesity [16]. A recent cross-sectional study of highly educated adults conducted by Mansouri et al. [23] demonstrated that serum 25(OH)D levels were negatively correlated with WC, and that participants with VDD had a 2.04-fold greater risk of central obesity than those with normal levels of 25(OH)D. Several RCTs have investigated the effects of vitamin D supplementation on WC and WHR [24-26]; however, the results are still under debate. Moreover, until now, we have not found any metaanalyses in the worldwide epidemiological literature investigating the quantitative association between vitamin $\mathrm{D}$ supplementation and central obesity indices.

Given this background, the aim of this study was to examine whether an improvement in vitamin $\mathrm{D}$ status correlated with reduced obesity indices in order to make informed decisions on the administration of vitamin D. Therefore, we conducted a meta-analysis of 20 RCTs involving apparently healthy populations who reportedly did not participate in any weight loss programs.

\section{Methods}

This systematic review with a meta-analysis was registered, and its protocol was published at the PROSPERO International Prospective Register of Systematic Reviews (www.crd.york.ac.uk/ PROSPERO/CRD42019130375). We conducted the study following the guidelines of the Preferred Reporting Items for Systematic Reviews and Meta-Analyses (PRISMA) [27]. The complete PRISMA checklist is provided in online supplementary Material Table S1 (see www.karger.com/doi/10.1159/000507418 for all online suppl. material).

Data Sources and Literature Search Strategies

The searches were conducted by L.D. and Y.W. from January 1995 to December 2019 using Pubmed, Embase, Web of Knowl- 
edge and Chinese National Knowledge Infrastructure databases with the following keywords or MeSH terms: "vitamin D," "cholecalciferol," "calcifediol," "ergocalciferol," "25(OH)D," " $1,25(\mathrm{OH})_{2} \mathrm{D}$," "25-hydroxyvitamin D," "1,25-dihydroxyvitamin D," "vitamin D supplementation," "body mass index," "BMI," "waist circumference," "WC," "waist to hip ratio," "WHR," "obesity," "abdominal obesity," "overweight" and "adiposity." Further, the records were restricted to publications in English or Chinese and human studies. To complement the electronic search, we also perused studies included in relevant systematic reviews and reference lists of pertinent articles. Details on the literature search strategy are described in online supplementary Table S2.

\section{Inclusion and Exclusion Criteria}

Two authors (L.D. and Y.W.) independently reviewed the titles and abstracts to identify articles for potentially relevant sources. Full texts of them were requested to evaluate eligibility. Articles were included if they met the following criteria: (1) followed an RCT design; (2) investigated the association between vitamin D supplementation and effect of obesity indices; (3) included a general healthy population rather than specific disease patients; (4) separately reported changes in the BMI, WC or WHR in the intervention and control groups before and after the intervention. We excluded studies if: (1) data were not fully available after contacting the authors by e-mail; (2) they were meta-analyses or systematic reviews; (3) they were duplicate studies; (4) participants were children, pregnant women or subjects diagnosed with a chronic medical illness; (5) participants engaged in special occupations; (6) subjects participated in any kind of weight loss program, including bariatric surgery, weight-reducing drugs or exercise. Discrepancies between 2 authors were solved by discussion and after reaching a consensus with the third author (L.H.).

\section{Data Extraction}

Data on the studies' characteristics and related information were collected in Excel format using a premade checklist by one reviewer (L.D.), and then double-checked by another author (Y.W.). The following information was extracted: (1) information of study (surname of the first author, year of publication, region of study, sample size of each group, intervention type and amount, duration of intervention and intervention combined with calcium or not); (2) characteristics of participants (age, gender, 25[OH]D levels at baseline and health status of participants); (3) changes in the BMI, WC, WHR or $25(\mathrm{OH}) \mathrm{D}$ in the intervention and control groups before and after the intervention. Attempts were made to contact the corresponding or first author for unavailable information.

\section{Risk for Bias Assessment}

Two authors (L.D. and Y.W.) independently assessed the quality of all included studies by following the Cochrane Collaboration's tool [28] (online suppl. Table S3). Seven aspects (random sequence generation, allocation concealment, blinding of participants and personnel, blinding of outcome assessment, incomplete outcome data, selective reporting and other bias) were estimated. Summary assessments for studies were assigned as "high," "low" or "unclear" according to the risk bias in each important outcome. Disagreements were solved through group discussion.

Data Synthesis and Statistical Analysis

The weighted mean difference (WMD) and 95\% confidence interval (CI) were used to assess the combined changes in BMI,
WC, WHR and 25(OH)D from baseline to follow-up between the randomly assigned intervention and placebo groups. If the SE was reported for the variation in the mean, we calculated the corresponding standard deviation (SD) by multiplying by $\sqrt{ } n$. If the mean and SD for changes in BMI, WC, WHR and $25(\mathrm{OH}) \mathrm{D}$ before and after intervention were not reported, we calculated them based on the following formula, described in the Cochrane Handbook for Systematic Reviews of Interventions [28]:

$$
\begin{aligned}
& \mathrm{Mean}_{\text {change }}=\mathrm{Mean}_{\text {final }}-\mathrm{Mean}_{\text {baseline }} \\
& \mathrm{SD}_{\text {change }}=\sqrt{ } \mathrm{SD}_{\text {baseline }}^{2}+\mathrm{SD}_{\text {final }}^{2}-\left(2 \times \text { Corr } \times \mathrm{SD}_{\text {baseline }} \times\right. \\
& \left.\mathrm{SD}_{\text {final }}\right) .
\end{aligned}
$$

The correlation coefficient (Corr) was estimated based on calculations of other parameters which provided complete data for $\mathrm{SD}_{\text {baseline }}, \mathrm{SD}_{\text {final }}, \mathrm{SD}_{\text {change }}$ in both the intervention and placebo groups.

Statistical heterogeneity between different studies was measured using $\chi^{2}$-based $Q$ and $I^{2}$ statistics. Depending on the heterogeneity, either a fixed-effect model or a random-effect model was adopted (if the heterogeneity $I^{2}$ was above $50 \%$, the random-effect model was used; otherwise, the fixed-effect model was applied). Separate meta-analyses were carried out for different subgroups including gender, region, duration of intervention, dose of intervention, vitamin D status at baseline (VDD or not), baseline BMI ( $\geq 30$ or not), risk of bias (high, low or unclear) and whether it was combined with $\mathrm{Ca}$ administration (yes or no).

Sensitivity analyses were performed to assess the robustness of the summary estimates by omitting 1 study at a time and repeating the meta-analysis with the rest. Publication bias was assessed through visual inspection of Begg's funnel plots and by Egger's linear regression tests. If some publication bias was detected, the trim-and-fill method was used to adjust the meta-analysis results by adding data from potential missing studies [29]. $p$ values $<0.05$ were considered statistically significant. Analyses were performed using the Stata 12.0 statistical software package.

\section{Results}

\section{Study Selection and Characteristics}

Of the 1,412 studies identified, 20 studies were selected for the present meta-analysis. They included 24 intervention groups with 3,153 participants ( $n=1,768$ in the intervention group and $n=1,385$ in the placebo group). Of these, 20 articles investigated vitamin $\mathrm{D}$ supplementation and BMI changes [17-19, 24-26, 30-43], 12 articles studied vitamin D supplementation and WC changes $[17,18$, 24-26, 32, 36, 37, 40-43], 6 articles investigated vitamin D supplementation and WHR changes [19, 24-26, 31, 42], and 7 articles studied vitamin $\mathrm{D}$ supplementation and serum 25(OH)D changes [19, 24, 30-32, 36, 37] (Table 1). A list of the excluded articles and the reasons for exclusion is shown in the flow chart (Fig. 1).

All participants were considered healthy, except for the fact that part of them suffered from simple obesity. 
Table 1. Characteristics of included RCT studies

\begin{tabular}{|c|c|c|c|c|c|c|c|c|c|}
\hline \multirow[t]{2}{*}{ Author, year } & \multirow[t]{2}{*}{$\begin{array}{l}\text { Study } \\
\text { region }\end{array}$} & \multirow[t]{2}{*}{$\begin{array}{l}\text { Sample } \\
\text { size, } n\end{array}$} & \multirow{2}{*}{$\begin{array}{l}\text { Vitamin D } \\
\text { dose, } \\
\text { IU/day }\end{array}$} & \multirow{2}{*}{$\begin{array}{l}\text { Study } \\
\text { duration, } \\
\text { months }\end{array}$} & \multicolumn{4}{|c|}{$\begin{array}{l}\text { Report measures } \\
\text { of obesity/25(OH)D }\end{array}$} & \multirow[t]{2}{*}{$\begin{array}{l}\text { Total } \\
\text { bias }^{\mathrm{a}}\end{array}$} \\
\hline & & & & & BMI & WC & WHR & $25(\mathrm{OH}) \mathrm{D}$ & \\
\hline Major [43], 2007 & Canada & 63 & 200 & 3.75 & $\sqrt{ }$ & $\sqrt{ }$ & & & Low \\
\hline Pittas [30], 2007 & USA & 222 & 700 & 36 & $\sqrt{ }$ & & & $\sqrt{ }$ & Unclear \\
\hline Nagpal [24], 2008 & India & 71 & 8,571 & 1.5 & $\sqrt{ }$ & $\sqrt{ }$ & $\sqrt{ }$ & $\sqrt{ }$ & High \\
\hline Sneve [31], 2008 & Norway & 292 & 2,857 & 12 & $\sqrt{ }$ & & $\sqrt{ }$ & $\sqrt{ }$ & Low \\
\hline Sneve [31], 2008 & Norway & 302 & 5,714 & 12 & $\sqrt{ }$ & & $\sqrt{ }$ & $\sqrt{ }$ & Low \\
\hline $\begin{array}{l}\text { Zittermann [32], } \\
2009\end{array}$ & Germany & 165 & 3,332 & 12 & $\sqrt{ }$ & $\sqrt{ }$ & & $\sqrt{ }$ & Low \\
\hline Zhou [33], 2010 & USA & 542 & 1,100 & 48 & $\sqrt{ }$ & & & & Low \\
\hline $\begin{array}{l}\text { Kjærgaard [34], } \\
2011\end{array}$ & Norway & 230 & 5,714 & 6 & $\sqrt{ }$ & & & & High \\
\hline Zhu [35], 2012 & Georgia & 37 & 2,000 & 4 & $\sqrt{ }$ & & & & Low \\
\hline $\begin{array}{l}\text { Salehpour [36], } \\
2012\end{array}$ & Iran & 77 & 1,000 & 3 & $\sqrt{ }$ & $\sqrt{ }$ & & $\sqrt{ }$ & Low \\
\hline $\begin{array}{l}\text { Rosenblum [37], } \\
2012\end{array}$ & USA & 71 & 100 & 4 & $\sqrt{ }$ & $\sqrt{ }$ & & $\sqrt{ }$ & Low \\
\hline $\begin{array}{l}\text { Rosenblum [37], } \\
2012\end{array}$ & USA & 83 & 100 & 4 & $\sqrt{ }$ & $\sqrt{ }$ & & $\sqrt{ }$ & Low \\
\hline Forsythe [38], 2012 & Ireland & 118 & 600 & 5.5 & $\sqrt{ }$ & & & & High \\
\hline Forsythe [38], 2012 & Ireland & 109 & 600 & 5.5 & $\sqrt{ }$ & & & & High \\
\hline Wood [39], 2012 & UK & 204 & 400 & 12 & $\sqrt{ }$ & & & & Low \\
\hline Wood [39], 2012 & UK & 203 & 1,000 & 12 & $\sqrt{ }$ & & & & Low \\
\hline $\begin{array}{l}\text { Wamberg [40], } \\
2013\end{array}$ & Denmark & 52 & 7,000 & 6.5 & $\sqrt{ }$ & $\sqrt{ }$ & & & High \\
\hline Zhu [41], 2013 & China & 43 & 125 & 3 & $\sqrt{ }$ & $\sqrt{ }$ & & & High \\
\hline Mitchell [42], 2015 & USA & 90 & 5,714 & 3 & $\sqrt{ }$ & & $\sqrt{ }$ & & Low \\
\hline Sun $[18], 2016$ & Japan & 95 & 420 & 12 & $\sqrt{ }$ & $\sqrt{ }$ & & & Low \\
\hline Tepper [17], 2016 & Israel & 130 & 1,666 & 12 & $\sqrt{ }$ & $\sqrt{ }$ & & & Unclear \\
\hline Mousa [19], 2017 & Australia & 54 & 4,000 & 4 & $\sqrt{ }$ & & $\sqrt{ }$ & $\sqrt{ }$ & Low \\
\hline Khosravi [25], 2018 & Iran & 53 & 7,142 & 1.5 & $\sqrt{ }$ & $\sqrt{ }$ & $\sqrt{ }$ & & Unclear \\
\hline $\begin{array}{l}\text { Al-Bayyari [26], } \\
2018\end{array}$ & Jordan & 98 & 7,142 & 2 & $\sqrt{ }$ & $\sqrt{ }$ & $\sqrt{ }$ & & Low \\
\hline
\end{tabular}

BMI, body mass index; WC, waist circumference; WHR, waist-to-hip ratio; $n$, number of participants in each study; 25(OH)D, 25-hydroxyvitamin D. ${ }^{a}$ Risk for bias assessed by following the Cochrane Collaboration's tool.

The majority of studies were conducted with female or mixed (male/female) participants; only 2 studies included male subjects only $[17,24]$ (Table 2). The daily doses of vitamin D supplementation varied from 100 to $8,571 \mathrm{IU} /$ day. The duration of supplementation ranged from 1.5 to 36 months (Table 1). Assessments of bias risk for included trials are shown in online supplementary Table S3. All studies had low risk of bias for incomplete outcome data and selective reporting. There was insufficient information about random sequence generation in 4 studies [24, $25,38,43$ ] and high risk of bias in one study [34]. Three studies had high risk of bias for blinding of participants and personnel and outcome assessment [34, 38, 41]. In 2 studies, risk of allocation concealment was unclear [41], and one was high [34].

\section{Meta-Analysis of General Obesity}

A forest plot showing the effects of vitamin D supplementation on the BMI changes was constructed, including data from 20 RCTs. Overall, no effect of vitamin D supplementation on BMI change was found (pooled WMD $-0.09 \mathrm{~kg} / \mathrm{m}^{2} ; 95 \%$ CI -0.19 to $0.01 ; p=0.08 ; I^{2}=$ $63.1 \%$, $p_{\text {heterogeneity }}<0.001$; Fig. 2). Considering this borderline significance and the moderate heterogeneity, subgroup meta-analysis was conducted to investigate interactions based on the characteristics of the participants 


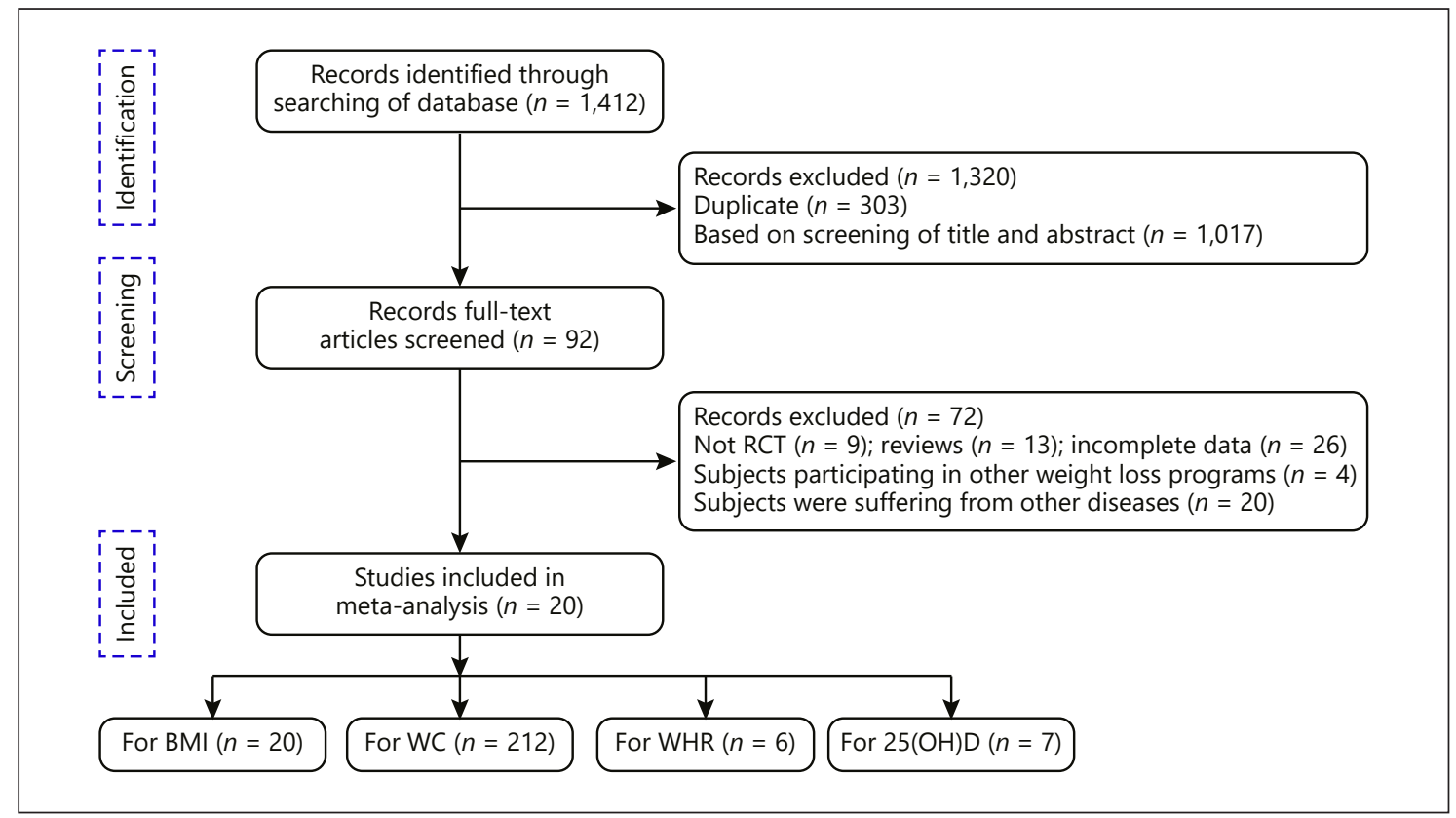

Fig. 1. Flow chart showing the article selection process.

\begin{tabular}{|c|c|c|}
\hline Study & WMD (95\% Cl) & Weight (\%) \\
\hline Pittas (2007) & $0.03(-0.30,0.36)$ & 4.81 \\
\hline Major (2007) & $0.40(-1.21,2.01)$ & 0.36 \\
\hline Nagpal (2008) & $0.02(-0.28,0.32)$ & 5.22 \\
\hline Sneve (2008) & $-0.10(-0.39,0.19)$ & 5.47 \\
\hline Zittermann (2009) & $0.20(-0.40,0.80)$ & 2.17 \\
\hline Zhou (2010) & $-0.11(-0.16,-0.06)$ & 9.94 \\
\hline Kjærgaard (2011) & $-0.03(-0.23,0.17)$ & 7.14 \\
\hline$\longrightarrow$ & $-0.87(-1.38,-0.36)$ & 2.73 \\
\hline Salehpour (2012) & $-0.09(-0.36,0.18)$ & 5.84 \\
\hline Rosenblum (2012) & $0.14(-0.41,0.69)$ & 2.44 \\
\hline Rosenblum (2012) & $-0.20(-0.76,0.36)$ & 2.35 \\
\hline Forsythe (2012) & $0.12(-0.03,0.27)$ & 8.27 \\
\hline Forsythe (2012) & $0.06(-0.17,0.29)$ & 6.60 \\
\hline Wood (2012) & $-0.07(-0.39,0.25)$ & 4.98 \\
\hline Wamberg (2013) & $-0.30(-1.51,2.11)$ & 0.29 \\
\hline Zhu (2013) & $-0.30(-0.76,0.16)$ & 3.15 \\
\hline Mitchell (2015) & $0.30(0.01,0.59)$ & 5.45 \\
\hline Sun (2016) & $0.00(-0.16,0.16)$ & 8.05 \\
\hline Tepper (2016) & $-0.14(-0.45,0.17)$ & 5.07 \\
\hline Mousa (2017) & $-0.10(-0.67,0.47)$ & 2.33 \\
\hline Khosravi (2018) & $-0.63(-0.90,-0.36)$ & 5.81 \\
\hline Al-Bayyari (2018) & $-1.30(-2.04,-0.56)$ & 1.52 \\
\hline Overall $\left(I^{2}=63.1 \%, p=0.000\right)$ & $-0.09(-0.19,0.01)$ & 100.00 \\
\hline-2.11 & 2.11 & \\
\hline
\end{tabular}

Fig. 2. Forest plot of the effects of vitamin D supplementation on BMI [17-19, 24-26, 30-43]. 
Table 2. Characteristics of participants

\begin{tabular}{|c|c|c|c|c|c|c|c|}
\hline Author, year & Participant characteristics & age, years & gender/n & $\begin{array}{l}\text { baseline } 25(\mathrm{OH}) \mathrm{D} \\
\text { level, } \mathrm{ng} / \mathrm{mL}^{\mathrm{a}}\end{array}$ & age, years & gender/n & $\begin{array}{l}\text { baseline } 25(\mathrm{OH}) \mathrm{D} \\
\text { level, } \mathrm{ng} / \mathrm{mL}^{\mathrm{a}}\end{array}$ \\
\hline Major [43], 2007 & Healthy, overweight or obese women & $43.6 \pm 5$ & $\mathrm{~F} / 30$ & - & $41.6 \pm 6.1$ & $\mathrm{~F} / 33$ & - \\
\hline Pittas [30], 2007 & Nondiabetic adults & $70.6 \pm 4.2$ & $\mathrm{~B} / 108$ & $32.61 \pm 15.4$ & $71.7 \pm 4.2$ & $\mathrm{~B} / 104$ & $28.29 \pm 11.66$ \\
\hline Nagpal [24], 2008 & Apparently healthy men & $42.4 \pm 6.6$ & $\mathrm{M} / 30$ & $14.62 \pm 5.83$ & $45.0 \pm 9.2$ & $36 / 0$ & $12.02 \pm 5$ \\
\hline $\begin{array}{l}\text { Zittermann [32], } \\
2009\end{array}$ & Healthy overweight subjects & $47.4 \pm 10.3$ & $\mathrm{~B} / 82$ & $12.02 \pm 7.0$ & $48.8 \pm 10.1$ & $\mathrm{~B} / 83$ & $12.14 \pm 8.0$ \\
\hline Zhou [33], 2010 & Postmenopausal women in good health & $66.5 \pm 7.5$ & $\mathrm{~F} / 336$ & $29.29 \pm 7.53$ & $65.2 \pm 6.5$ & $\mathrm{~B} / 206$ & $27.92 \pm 10.23$ \\
\hline $\begin{array}{l}\text { Kjærgaard [34], } \\
2011\end{array}$ & Adults with low levels of serum $25(\mathrm{OH}) \mathrm{D}$ & $53.4 \pm 10.3$ & $\mathrm{~B} / 120$ & $18.99 \pm 6.33$ & $53.3 \pm 10.1$ & $\mathrm{~B} / 110$ & $19.11 \pm 6.21$ \\
\hline Zhu [35], 2012 & Apparently healthy adults & $31.1 \pm 10$ & $\mathrm{~B} / 19$ & $14.18 \pm 4.53$ & $31.9 \pm 10.3$ & $\mathrm{~B} / 18$ & $16.31 \pm 6.29$ \\
\hline Forsythe [38], 2012 & Healthy young adults & $28 \pm 5.6$ & $\mathrm{~B} / 56$ & $30.4(22.3-35.9)$ & $29 \pm 5$ & $\mathrm{~B} / 62$ & $26.5(22.6-38.6)$ \\
\hline Forsythe [38], 2012 & Healthy older adults & $71 \pm 5.3$ & $\mathrm{~B} / 51$ & $22.0(15.4-27.9)$ & $68 \pm 6.2$ & $\mathrm{~B} / 58$ & $23.2(16.1-31.5)$ \\
\hline Wood [39], 2012 & Healthy postmenopausal women & $63.5 \pm 1.9$ & $\mathrm{~F} / 102$ & $13.12 \pm 5.1$ & $63.9 \pm 2.3$ & $\mathrm{~F} / 102$ & $14.5 \pm 6.85$ \\
\hline Wood [39], 2012 & & $64.1 \pm 2.3$ & $\mathrm{~F} / 101$ & $13.0 \pm 4.66$ & & & \\
\hline Wamberg [40], 2013 & Healthy obese adults & $39.5 \pm 8$ & $\mathrm{~B} / 26$ & $34.5 \pm 10.8$ & $41.2 \pm 6.8$ & $\mathrm{~F} / 26$ & $13.62 \pm 3.61$ \\
\hline Zhu [41], 2013 & Generally healthy adults & $20.1 \pm 11.1$ & $\mathrm{~B} / 22$ & - & $20.3 \pm 0.8$ & $\mathrm{~B} / 21$ & - \\
\hline Mitchell [42], 2015 & Healthy adults with low vitamin D & $28 \pm 7$ & $\mathrm{~B} / 40$ & $18 \pm 7$ & $29 \pm 9$ & $\mathrm{~B} / 50$ & - \\
\hline Sun [18], 2016 & Healthy adults & $27-57$ & $\mathrm{~B} / 48$ & $13.14 \pm 1.12$ & $29-58$ & $\mathrm{~B} / 47$ & $12.82 \pm 1.12$ \\
\hline Tepper [17], 2016 & Healthy men & - & $\mathrm{M} / 78$ & $15.3 \pm 3.46$ & - & $\mathrm{M} / 52$ & $15.41 \pm 3.49$ \\
\hline Mousa [19], 2017 & Healthy but overweight or obese & $30.5 \pm 6$ & $\mathrm{~B} / 28$ & $12.58 \pm 5.05$ & $29.5 \pm 7$ & $\mathrm{~B} / 26$ & $13.7 \pm 4.0$ \\
\hline Khosravi [25], 2018 & Overweight and obese women & $29.1 \pm 9.6$ & $\mathrm{~F} / 26$ & - & $26.9 \pm 9.1$ & $\mathrm{~F} / 27$ & - \\
\hline
\end{tabular}

F, female; M, male; B, both female and male; $n$, number of females, males or both; -, not reported. an order to facilitate calculation and reduce heterogeneity, 25(OH)D units were unified, 25(OH)D in $\mathrm{ng} / \mathrm{mL}$ could be converted to $\mathrm{nmol} / \mathrm{L}$ by multiplying by 2.5 .

and intervention. These results suggested that variables including gender, region where the study was conducted, intervention duration, baseline BMI and risk of bias could be the potential source of the heterogeneity. Notable findings from the subgroup analysis included beneficial effects of supplementing vitamin D on the BMI decline when participants were female, when the study was conducted in Asia, and when the intervention duration was $\geq 6$ months $(p<0.026$; Table 3$)$.

\section{Meta-Analysis of Central Obesity}

A forest plot showing the effects of vitamin D supplementation on the WC changes was constructed, including data from 11 RCTs. There was no statistically significant difference between the intervention and placebo groups for WC changes (pooled WMD $-0.71 \mathrm{~cm}$; $95 \%$ CI -1.58 to $0.16 ; p=0.112 ; I^{2}=68.0 \%$, $p_{\text {heterogeneity }}<0.001$; Fig. 3a). Subgroup analysis demonstrated that heterogeneity decreased in the following subgroups: male, European region, BMI $\geq 30$ at baseline, non-VDD at baseline, duration of intervention $\geq 6$ months, and bias at high risk (Table 3). Similarly, notable findings from the subgroup analysis included beneficial effects of vitamin D supplementation on the WC reduction when participants were female, when the study was conducted in Asia, and when the duration of the intervention was $\geq 6$ months ( $p<$ 0.003 ; Table 3 ). When compared with the placebo group, however, the pooled meta-analysis and subgroup analysis all indicated that there was no effect of vitamin D supplementation on WHR changes (pooled WMD 0.00; 95\% CI 


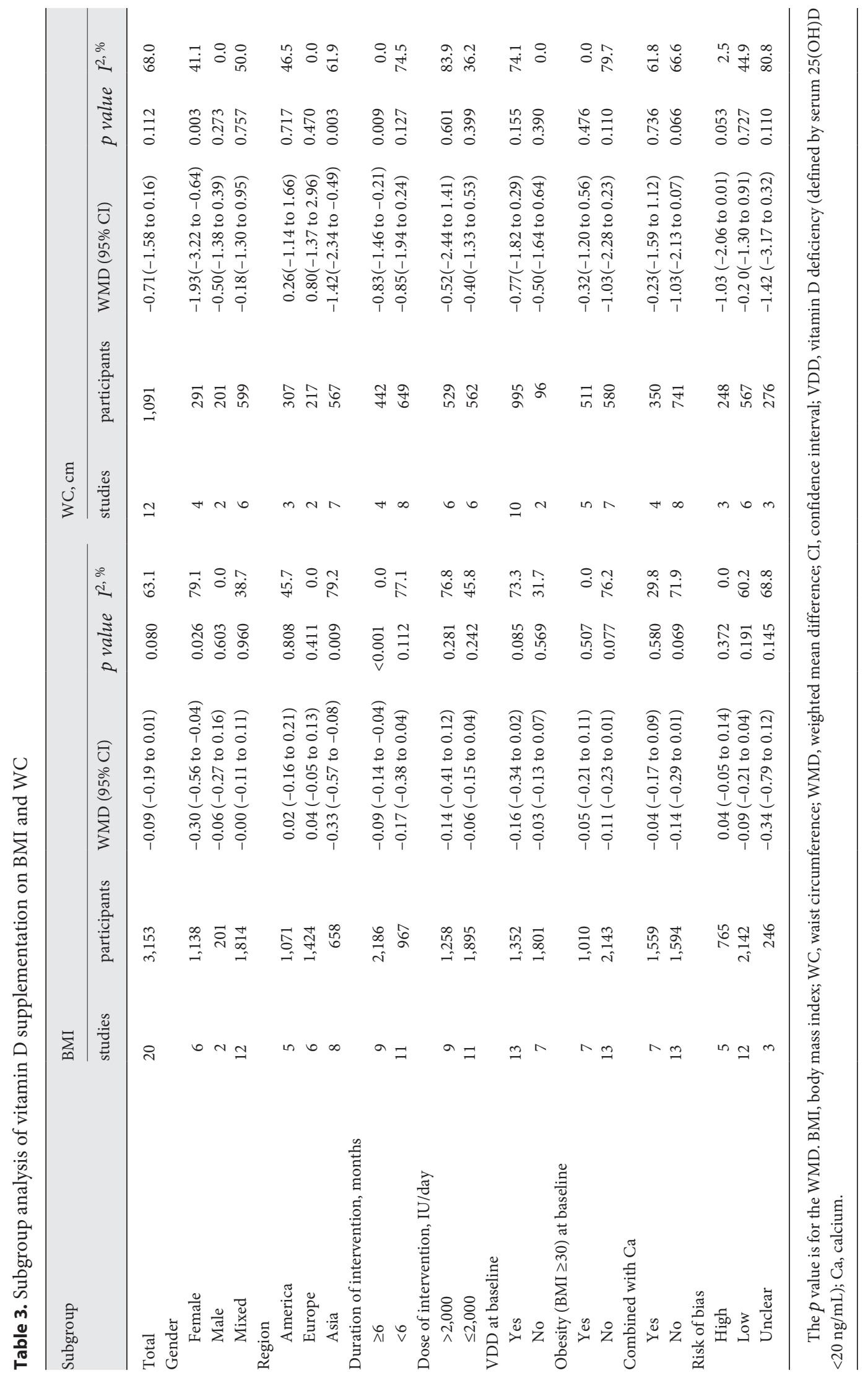




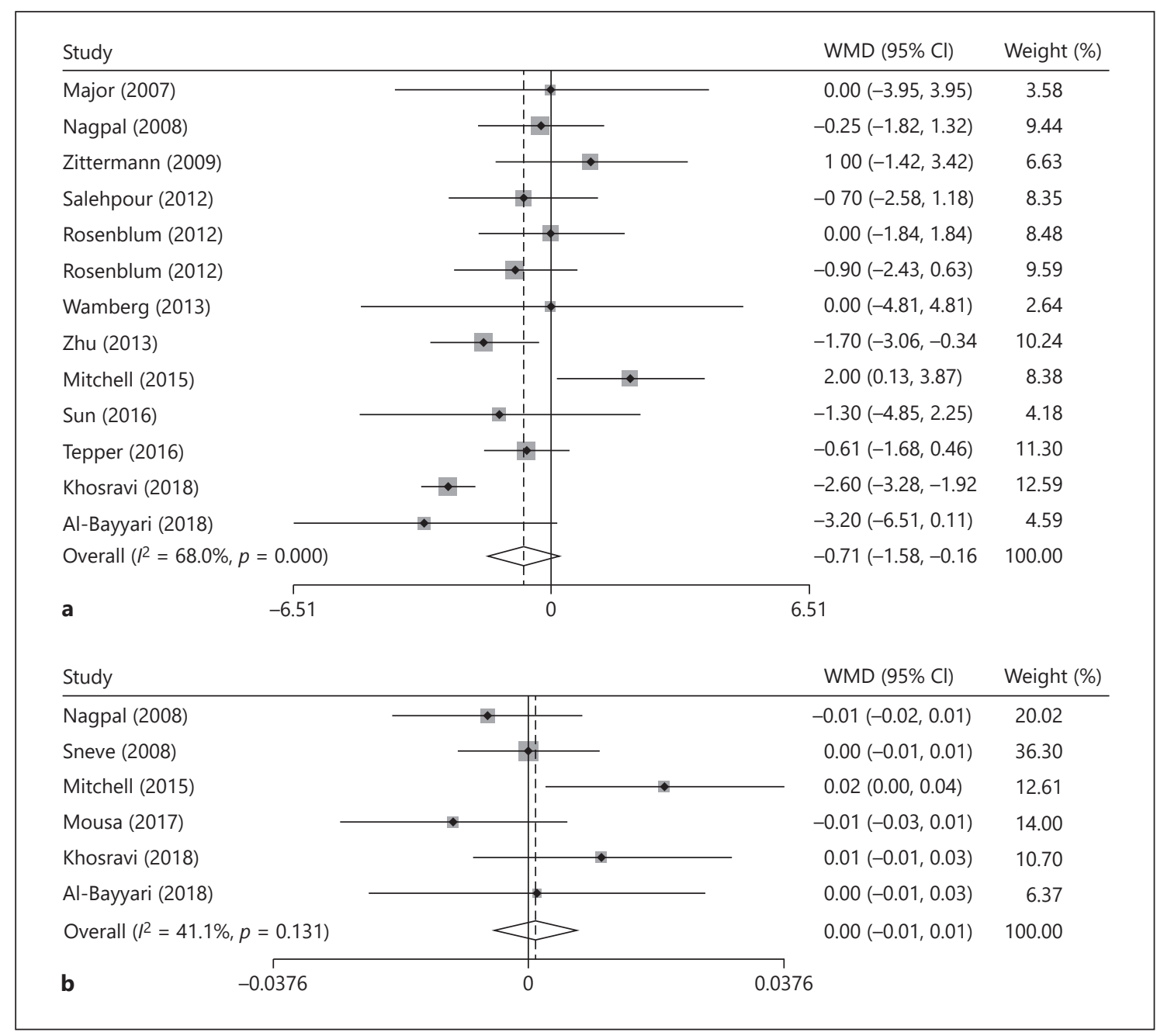

Fig. 3. Forest plots of the effects of vitamin D supplementation on WC [17, 18, 24-26, 32, 36, 37, 40-43] (a) and WHR [19, 24-26, 31, 42] (b).

-0.01 to $0.01 ; p=0.749$; Fig. $3 b$; online suppl. Table S4). In addition, no heterogeneity was detected $\left(I^{2}=41.1 \%\right.$; $p_{\text {heterogeneity }}=0.131$; Fig. $3 \mathrm{~b}$ ).

\section{Meta-Analysis of Serum 25(OH)D}

A forest plot showing the effects of vitamin D supplementation on serum $25(\mathrm{OH}) \mathrm{D}$ changes was constructed, including data from 7 RCTs. Following vitamin D supplementation, there was a significant beneficial effect on serum 25(OH)D levels (pooled WMD $13.20 \mathrm{ng} / \mathrm{mL}$; 95\% CI 9.83-16.58; $p<0.001 ; I^{2}=75.7 \%$, $p_{\text {heterogeneity }}<0.001$; Fig. 4). Subgroup analysis demonstrated that heterogeneity decreased in the subgroups of studies conducted in European and Asian regions, and those with BMI $<30$ at baseline (Table 4).

\section{Sensitivity and Publication Bias Analyses}

Sensitivity analysis utilizing the leave-one-out method did not show any major change on primary outcomes, an indication of the good stability of the results. Neither Begg's test nor Egger's test showed significant publication bias with respect to the effects of vitamin $D$ supplementation on $\operatorname{BMI}(t=-0.19, p=0.852)$, WHR $(t=-0.60, p=0.582)$ and $25(\mathrm{OH}) \mathrm{D}(t=-1.29, p=0.245$; online suppl. Table S5 and Fig. S1). Considering the borderline significance for the publication bias in WC $(t=2.20, p=0.050)$, the trim-andfill method was applied to adjust the results. However, this methodology indicated that after 2-step iterations, the number of missing studies was 0 . No alterations were found in the adjusted WMD and $95 \%$ CI $(-0.71 \mathrm{~cm},[-1.58$ to $0.17])$. Therefore, the outcome was stable in terms of WC. 


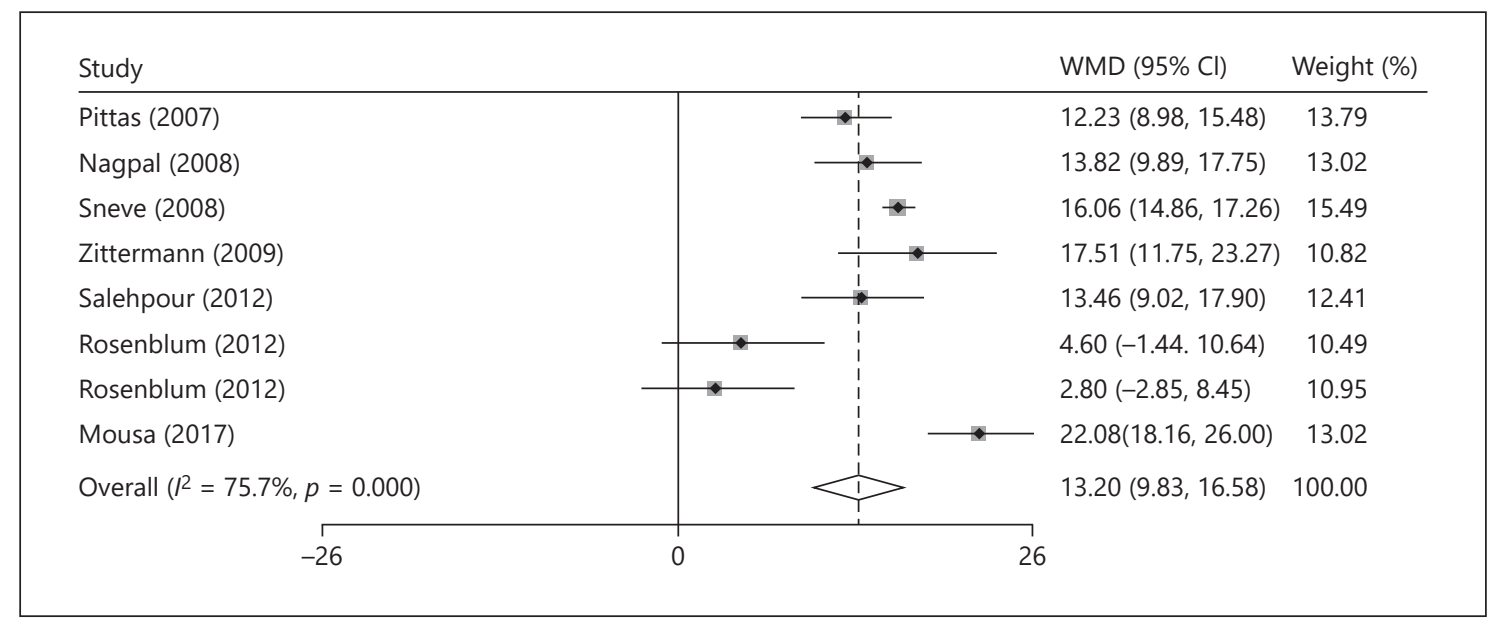

Fig. 4. Forest plots of the effects of vitamin D supplementation on serum 25(OH)D [19, 24, 30-32, 36, 37].

Table 4. Subgroup analysis of vitamin D supplementation on $25(\mathrm{OH}) \mathrm{D}(\mathrm{ng} / \mathrm{mL})$

\begin{tabular}{|c|c|c|c|c|c|}
\hline Subgroup & Studies & Participants & WMD (95\% CI) & p value & $I^{2, \%}$ \\
\hline Total & 7 & 1,188 & $13.20(9.83-16.58)$ & $<0.001$ & 75.7 \\
\hline \multicolumn{6}{|l|}{ Gender } \\
\hline Female & 1 & 77 & $13.46(9.02-17.90)$ & $<0.001$ & 0.0 \\
\hline Male & 1 & 71 & $13.82(9.89-17.75)$ & $<0.001$ & 0.0 \\
\hline Mixed & 5 & 1,040 & $12.93(8.40-17.46)$ & $<0.001$ & 89.5 \\
\hline \multicolumn{6}{|l|}{ Location } \\
\hline America & 2 & 376 & $6.91(0.42-13.40)$ & 0.037 & 80.9 \\
\hline Europe & 2 & 610 & $16.12(14.95-17.29)$ & $<0.001$ & 0.0 \\
\hline Asia & 2 & 148 & $13.66(10.72-16.60)$ & $<0.001$ & 0.0 \\
\hline Australia & 1 & 54 & $22.08(18.16-26.00)$ & $<0.001$ & 0.0 \\
\hline \multicolumn{6}{|c|}{ Duration of intervention, months } \\
\hline$\geq 6$ & 3 & 832 & $15.07(12.24-17.89)$ & $<0.001$ & 60.9 \\
\hline$<6$ & 4 & 356 & $11.60(4.97-18.23)$ & 0.001 & 90.1 \\
\hline \multicolumn{6}{|c|}{ Dose of intervention, IU/day } \\
\hline$>2,000$ & 4 & 736 & $17.20(14.08-20.32)$ & $<0.001$ & 70.5 \\
\hline$\leq 2,000$ & 3 & 452 & $8.69(3.71-13.65)$ & 0.001 & 77.7 \\
\hline \multicolumn{6}{|c|}{ VDD at baseline } \\
\hline Yes & 4 & 367 & $16.73(12.40-21.05)$ & $<0.001$ & 73.7 \\
\hline No & 3 & 821 & $9.49(3.61-15.36)$ & 0.002 & 91.4 \\
\hline \multicolumn{6}{|c|}{ Obesity (BMI $\geq 30)$ at baseline } \\
\hline Yes & 5 & 1,003 & $13.12(8.38-17.86)$ & 0.476 & 88.8 \\
\hline No & 2 & 185 & $12.88(10.37-15.38)$ & 0.110 & 0.0 \\
\hline \multicolumn{6}{|c|}{ Combined with $\mathrm{Ca}$} \\
\hline Yes & 3 & 821 & $9.49(3.61-15.36)$ & 0.002 & 91.4 \\
\hline No & 4 & 367 & $16.73(12.40-21.05)$ & $<0.001$ & 73.7 \\
\hline \multicolumn{6}{|l|}{ Risk of bias } \\
\hline High & 1 & 222 & $12.23(8.98-15.48)$ & $<0.001$ & 0.0 \\
\hline Low & 6 & 966 & $13.12(8.38-17.86)$ & $<0.001$ & 88.8 \\
\hline
\end{tabular}

The $p$ value is for the WMD. WMD, weighted mean difference; CI, confidence interval; VDD, vitamin D deficiency (defined by serum 25[OH]D $<20 \mathrm{ng} / \mathrm{mL}$ ); Ca, calcium. 


\section{Discussion}

There is great interest in investigating possible preventive effects of vitamin $\mathrm{D}$ beyond its traditional role in maintaining skeletal health. The possible role of vitamin $\mathrm{D}$ in the pathogenesis of obesity is an important topic for public health and for issuing clinical guidelines. However, based on the literature published to date in apparently healthy populations, our pooled results indicate nonperceptible effects of vitamin D supplementation in terms of reducing the BMI, WC and WHR.

These 3 obese indices (BMI, WC and WHR) are readily available, noninvasive and inexpensive, which can frequently be applied in epidemiological surveys and clinical practice. The most widely used anthropometric index, the BMI, reflects both fat and muscle mass, but it does not accurately represent the distribution of body fat, especially abdominal fat [44]. Therefore, several studies suggested that the additional measurement of WC and WHR is better than the BMI alone to identify individuals with obesity, distinguishing the types of obesity and examining the prevalence of various types of obesity $[16,45]$. To our knowledge, this is the first meta-analysis for the effects of vitamin D supplementation on general and central obesity indices in apparently healthy populations. Statistically, a potential reduction in BMI following vitamin D supplementation $(p=0.08)$ was noted as the sample size expands. However, such a small point estimate and narrow $\mathrm{CI}(-0.09,95 \% \mathrm{CI}-0.19$ to 0.01$)$, these puny effects would not be expected to have a clinical benefit. These results were consistent with previous studies that showed no significant effect on BMI change by use of vitamin D supplementation [46, 47]. The WC measures adipose tissue accumulation around the organs of the abdominal cavity. Abdominal fat is a good storage site for vitamin $\mathrm{D}$, inhibiting its release into the blood and reducing its bioavailability, which is the main explanation offered for VDD in individuals with obesity [9]. Nevertheless, in the present meta-analysis of 11 RCTs for WC and 6 RCTs for WHR, vitamin D treatment did not decrease the WC and WHR, with the WMD and 95\% CI $(-0.71 \mathrm{~cm}[-1.58$ to 0.16$], p=0.112$; and $0[-0.01$ to 0.01$]$, $p=0.749$, respectively). Although no obvious benefits of vitamin D supplementation were seen based on these 3 obesity indices, we found notable improvements in serum $25(\mathrm{OH}) \mathrm{D}$ levels after vitamin D supplementation, with a WMD of 13.20 $\mathrm{ng} / \mathrm{mL}$ and $95 \% \mathrm{CI}$ of $9.83-16.58(p<0.001)$. In agreement with our results, previous meta-analysis also showed a significant effect of vitamin $\mathrm{D}$ supplementation on serum $25(\mathrm{OH}) \mathrm{D}$ concentrations [48].

The overall results may be explained by several reasons. First, clinical trials that assess the effects of vitamin
D on obesity vary with different study designs. Therefore, the published studies are distinguished by methodologies, including participant characteristics, intervention times, intervention doses, as well as vitamin D formulations, making it difficult to pool the results. It is also a potential reason for the high heterogeneity of the present meta-analysis. Second, the utilization of vitamin D undergoes a series of physiological and biochemical processes, making it difficult to evaluate the ultimate bioavailability of participants [49]. Third, BMI, WC and WHR are all indirect indicators of obesity, making it hard to quantify amounts of fat accurately, and thus the direct effect of vitamin $\mathrm{D}$ supplementation on adipose tissue is hard to describe. Finally, $25(\mathrm{OH}) \mathrm{D}$ is an intermediate product of vitamin D metabolism which reflects circulating vitamin $\mathrm{D}$ levels in blood over a period of time. Production of $1,25(\mathrm{OH})_{2} \mathrm{D}_{3}$, an active form of vitamin $\mathrm{D}$, depends on the enzyme $1 \alpha$-hydroxylase, which catalyzes the synthesis of $1,25(\mathrm{OH})_{2} \mathrm{D}_{3}$ from $25(\mathrm{OH}) \mathrm{D}$ [15]. Following vitamin D supplementation, the likelihood that $25(\mathrm{OH})$ $\mathrm{D}$ will be used as a substrate in the catalytic reaction is reduced, so the levels of $25(\mathrm{OH}) \mathrm{D}$ in circulating blood will increase. This may be a reasonable explanation for the elevated serum 25(OH)D levels.

In any meta-analysis, the heterogeneous nature of the pooled results presents a challenge for the interpretation of any quantitative outcomes [47]. Subgroup analysis, a common method of exploring sources of heterogeneity, was performed in this study. Interestingly, when conducting a subgroup analysis in BMI and $\mathrm{WC}$, beneficial and more significant effects were found in the subgroup of females, Asia region studies, and duration of intervention $\geq 6$ months (all $p<0.026$ ). Reasonable explanations for the increased effect of vitamin $\mathrm{D}$ treatment in special groups may be the fact that obesity prevalence among women and Asians is higher than that in men and other areas $[50,51]$. In particular, Asians are more likely to have central fat deposition despite having a lower BMI $[52,53]$. Therefore, those participants have a more sensitive response to vitamin D supplementation and more easily display the beneficial effects. In addition, vitamin D must be administered for a certain period of time before changes in the BMI and WC become evident [54].

Some limitations of this analysis deserve consideration, including the inability to completely collect all related published papers. Moreover, the sample size of most included RCTs was low. Additionally, the effects of seasonality, vitamin $\mathrm{D}$ formulations and sun exposure were not evaluated. However, there are 2 important advantages that differentiate it from previous studies. All partici- 
pants were reported to be in good health (except for the simple obesity), therefore the results can be generalized to the general population. In addition, none of the subjects participated in any type of weight loss program (including exercise, weight loss medications or weight loss surgery). This maximizes the observed separate effect of vitamin D supplementation on obesity indicators.

\section{Conclusion}

In summary, this study is the first meta-analysis quantifying the effects of vitamin D supplementation on general and central obesity indices. Despite increased serum $25(\mathrm{OH}) \mathrm{D}$ levels, the obesity indices (BMI, WC and WHR) did not improve significantly. Therefore, the management and clinical application of vitamin $\mathrm{D}$ should be made with caution. However, it does not rule out that it may have potential clinical implication along with other weight loss programs.

\section{Acknowledgments}

We thank all the investigators in this study.

\section{Statement of Ethics}

The research was conducted ethically in accordance with the World Medical Association Declaration of Helsinki.

\section{Disclosure Statement}

The authors have no conflicts of interest to declare.

\section{Funding Sources}

No funding supports this work.

\section{Author Contributions}

Y.W. and L.H. contributed to the study conception and design. L.D. and Y.W. contributed to the acquisition of data, the development of the protocol and the drafting of the manuscript. L.D. and Y.Z. contributed to the analysis and interpretation of the quantitative data. L.D. and Q.L. contributed to the critical revising of the final draft. L.D. and L.W. contributed to the analysis and interpretation of the descriptive data and the revision of the final draft. All authors approved the final version.

\section{References}

1 World Health Organization. Fact sheet obesity and overweight 2016

2 Nansseu JR, Noubiap JJ, Bigna JJ. Epidemiology of overweight and obesity in adults living in cameroon: A systematic review and metaanalysis. Obesity (Silver Spring). 2019 Oct; 27(10):1682-92.

3 Gangloff A, Bergeron J, Lemieux I, Després JP. Changes in circulating vitamin D levels with loss of adipose tissue. Curr Opin Clin Nutr Metab Care. 2016 Nov;19(6):464-70.

4 Asghari G, Farhadnejad H, Hosseinpanah F, Moslehi N, Mirmiran P, Azizi F. Effect of vitamin D supplementation on serum 25-hydroxyvitamin D concentration in children and adolescents: a systematic review and meta-analysis protocol. BMJ Open. 2018 Sep; 8(9):e021636.

5 Ross AC, Manson JE, Abrams SA, Aloia JF, Brannon PM, Clinton SK, et al. The 2011 report on dietary reference intakes for calcium and vitamin D from the Institute of Medicine: what clinicians need to know. J Clin Endocrinol Metab. 2011 Jan;96(1):53-8.

6 Bassatne A, Chakhtoura M, Saad R, Fuleihan GE. Vitamin D supplementation in obesity and during weight loss: A review of randomized controlled trials. Metabolism. 2019 Mar; 92:193-205.
7 Rafiq S, Jeppesen PB. Body mass index, vitamin $\mathrm{d}$, and type 2 diabetes: A systematic review and meta-analysis. Nutrients. 2018 Aug; 10(9):E1182.

8 Pereira-Santos M, Costa PR, Assis AM, Santos CA, Santos DB. Obesity and vitamin D deficiency: a systematic review and meta-analysis. Obes Rev. 2015 Apr;16(4):341-9.

9 Wortsman J, Matsuoka LY, Chen TC, Lu Z, Holick MF. Decreased bioavailability of vitamin D in obesity. Am J Clin Nutr. 2000 Sep; 72(3):690-3.

10 Drincic AT, Armas LA, Van Diest EE, Heaney RP. Volumetric dilution, rather than sequestration best explains the low vitamin $\mathrm{D}$ status of obesity. Obesity (Silver Spring). 2012 Jul; 20(7):1444-8

11 Sergeev IN. Vitamin D-Cellular Ca2+ link to obesity and diabetes. J Steroid Biochem Mol Biol. 2016 Nov; 164:326-30.

12 Wen J, Hong Q, Wang X, Zhu L, Wu T, Xu P, et al. The effect of maternal vitamin $D$ deficiency during pregnancy on body fat and adipogenesis in rat offspring. Sci Rep. 2018 Jan; $8(1): 365$.

13 Ruiz-Ojeda FJ, Anguita-Ruiz A, Leis R, Aguilera CM. Genetic factors and molecular mechanisms of vitamin $\mathrm{d}$ and obesity relationship. Ann Nutr Metab. 2018;73(2):89-99.
14 Sergeev IN, Song Q. High vitamin D and calcium intakes reduce diet-induced obesity in mice by increasing adipose tissue apoptosis. Mol Nutr Food Res. 2014 Jun;58(6):1342-8.

15 Wamberg L, Christiansen T, Paulsen SK, Fisker S, Rask P, Rejnmark L, et al. Expression of vitamin D-metabolizing enzymes in human adipose tissue - the effect of obesity and diet-induced weight loss. Int J Obes. 2013 May;37(5):651-7.

16 Zhang YX, Wang ZX, Zhao JS, Chu ZH. The current prevalence and regional disparities in general and central obesity among children and adolescents in Shandong, China. Int J Cardiol. 2017 Jan;227:89-93.

17 Tepper S, Shahar DR, Geva D, Ish-Shalom S. Differences in homeostatic model assessment (HOMA) values and insulin levels after vitamin $\mathrm{D}$ supplementation in healthy men: a double-blind randomized controlled trial. Diabetes Obes Metab. 2016 Jun;18(6):633-7.

18 Sun X, Cao ZB, Tanisawa K, Ito T, Oshima S, Higuchi M. Vitamin D supplementation reduces insulin resistance in Japanese adults: a secondary analysis of a double-blind, randomized, placebo-controlled trial. Nutr Res. 2016 Oct;36(10):1121-9. 
19 Mousa A, Naderpoor N, de Courten MP, Teede H, Kellow N, Walker K, et al. Vitamin $\mathrm{D}$ supplementation has no effect on insulin sensitivity or secretion in vitamin D-deficient, overweight or obese adults: a randomized placebo-controlled trial. Am J Clin Nutr. 2017 Jun;105(6):1372-81.

20 Tabrizi R, Moosazadeh M, Lankarani KB, Akbari M, Heydari ST, Kolahdooz F, et al. The effects of vitamin D supplementation on metabolic profiles and liver function in patients with non-alcoholic fatty liver disease: A systematic review and meta-analysis of randomized controlled trials. Diabetes Metab Syndr. 2017 Dec;11 Suppl 2:S975-82.

21 Sangrós FJ, Torrecilla J, Giráldez-García C, Carrillo L, Mancera J, Mur T, et al. Association of general and abdominal obesity with hypertension, dyslipidemia and prediabetes in the predaps study. Rev Esp Cardiol (Engl Ed). 2018 Mar;71(3):170-7.

22 Traissac P, El Ati J. Trends in obesity, NHANES 2003-2004 to 2013-2014: is waist circumference increasing independently of bmi? Obesity (Silver Spring). 2019 Jul;27(7): 1043.

23 Mansouri M, Miri A, Varmaghani M, Abbasi $\mathrm{R}$, Taha P, Ramezani S, et al. Vitamin D deficiency in relation to general and abdominal obesity among high educated adults. Eat Weight Disord. 2019 Feb;24(1):83-90.

24 Nagpal J, Pande JN, Bhartia A. A doubleblind, randomized, placebo-controlled trial of the short-term effect of vitamin D3 supplementation on insulin sensitivity in apparently healthy, middle-aged, centrally obese men. Diabet Med. 2009 Jan;26(1):19-27.

25 Khosravi ZS, Kafeshani M, Tavasoli P, Zadeh AH, Entezari MH. Effect of vitamin D supplementation on weight loss, glycemic indices, and lipid profile in obese and overweight women: A clinical trial study. Int J Prev Med. 2018 Jul;9(1):63.

26 Al-Bayyari N, Al-Zeidaneen S, Hailat R, Hamadneh J. Vitamin D3 prevents cardiovascular diseases by lowering serum total homocysteine concentrations in overweight reproductive women: A randomized, placebo-controlled clinical trial. Nutr Res. 2018 Nov;59: 65-71.

27 Moher D, Liberati A, Tetzlaff J, Altman DG; PRISMA Group. Preferred reporting items for systematic reviews and meta-analyses: the PRISMA statement. BMJ. 2009 Jul;339:b2535.

28 Higgins JP, Green S. Cochrane Handbook for Systematic Reviews of Interventions Version 5.1.0. The Cochrane Collaboration 2011. www.handbook.cochrane.org.

29 Duval S, Tweedie R. Trim and fill: A simple funnel-plot-based method of testing and adjusting for publication bias in meta-analysis. Biometrics. 2000 Jun;56(2):455-63.

30 Pittas AG, Harris SS, Stark PC, DawsonHughes B. The effects of calcium and vitamin D supplementation on blood glucose and markers of inflammation in nondiabetic adults. Diabetes Care. 2007 Apr;30(4):980-6.
31 Sneve M, Figenschau Y, Jorde R. Supplementation with cholecalciferol does not result in weight reduction in overweight and obese subjects. Eur J Endocrinol. 2008 Dec;159(6): 675-84.

32 Zittermann A, Frisch S, Berthold HK, Götting C, Kuhn J, Kleesiek K, et al. Vitamin D supplementation enhances the beneficial effects of weight loss on cardiovascular disease risk markers. Am J Clin Nutr. 2009 May;89(5): 1321-7.

33 Zhou J, Zhao LJ, Watson P, Zhang Q, Lappe JM. The effect of calcium and vitamin D supplementation on obesity in postmenopausal women: secondary analysis for a large-scale, placebo controlled, double-blind, 4-year longitudinal clinical trial. Nutr Metab (Lond). 2010 Jul;7(1):62.

34 Kjærgaard M, Waterloo K, Wang CE, Almås B, Figenschau Y, Hutchinson MS, et al. Effect of vitamin D supplement on depression scores in people with low levels of serum 25-hydroxyvitamin D: nested case-control study and randomised clinical trial. Br J Psychiatry. 2012 Nov;201(5):360-8.

35 Zhu H, Guo D, Li K, Pedersen-White J, Stallmann-Jorgensen IS, Huang Y, et al. Increased telomerase activity and vitamin D supplementation in overweight African Americans. Int J Obes. 2012 Jun;36(6):805-9.

36 Salehpour A, Hosseinpanah F, Shidfar F, Vafa M, Razaghi M, Dehghani S, et al. A 12-week double-blind randomized clinical trial of vitamin $D_{3}$ supplementation on body fat mass in healthy overweight and obese women. Nutr J. 2012 Sep;11(1):78.

37 Rosenblum JL, Castro VM, Moore CE, Kaplan LM. Calcium and vitamin D supplementation is associated with decreased abdominal visceral adipose tissue in overweight and obese adults. Am J Clin Nutr. 2012 Jan;95(1): 101-8.

38 Forsythe LK, Livingstone MB, Barnes MS, Horigan G, McSorley EM, Bonham MP, et al. Effect of adiposity on vitamin D status and the 25-hydroxycholecalciferol response to supplementation in healthy young and older Irish adults. Br J Nutr. 2012 Jan;107(1):126-34.

39 Wood AD, Secombes KR, Thies F, Aucott L, Black AJ, Mavroeidi A, et al. Vitamin D3 supplementation has no effect on conventional cardiovascular risk factors: a parallel-group, double-blind, placebo-controlled RCT. J Clin Endocrinol Metab. 2012 Oct;97(10):3557-68.

40 Wamberg L, Kampmann U, Stødkilde-Jørgensen H, Rejnmark L, Pedersen SB, Richelsen B. Effects of vitamin D supplementation on body fat accumulation, inflammation, and metabolic risk factors in obese adults with low vitamin $D$ levels - results from a randomized trial. Eur J Intern Med. 2013 Oct;24(7):644-9.

41 Zhu W, Cai D, Wang Y, Lin N, Hu Q, Qi Y, et al. Calcium plus vitamin D3 supplementation facilitated fat loss in overweight and obese college students with very-low calcium consumption: a randomized controlled trial. Nutr J. 2013 Jan;12(1):8.
42 Mitchell DM, Leder BZ, Cagliero E, Mendoza $\mathrm{N}$, Henao MP, Hayden DL, et al. Insulin secretion and sensitivity in healthy adults with low vitamin $\mathrm{D}$ are not affected by high-dose ergocalciferol administration: a randomized controlled trial. Am J Clin Nutr. 2015 Aug; 102(2):385-92.

43 Major GC, Alarie F, Doré J, Phouttama S, Tremblay A. Supplementation with calcium + vitamin $\mathrm{D}$ enhances the beneficial effect of weight loss on plasma lipid and lipoprotein concentrations. Am J Clin Nutr. 2007 Jan; 85(1):54-9.

44 Gao W, Qiao X, Wang Y, Wan L, Wang Z, Wang $X$, et al. The interactive association of general obesity and central obesity with prevalent hypertension in rural lanzhou, China. PLoS One. 2016 Oct;11(10):e0164409.

$45 \mathrm{Wu}$ PS, Jordan SW, Hodson T, Chao AH Waist-to-hip ratio is a better predictor than body mass index for morbidity in abdominally based breast reconstruction. Microsurgery. 2018 Oct;38(7):731-7.

46 Mora N, Rieke K, Plitcha J, Segura A, Leehey D, DeShong K, et al. 25-Hydroxyvitamin D supplementation and BMI change: A metaanalysis of randomized controlled trials. J Obes Weight Loss Ther. 2013 Jul;3(4):181.

47 Chandler PD, Wang L, Zhang X, Sesso HD, Moorthy MV, Obi O, et al. Effect of vitamin D supplementation alone or with calcium on adiposity measures: a systematic review and meta-analysis of randomized controlled trials. Nutr Rev. 2015 Sep;73(9):577-93.

48 Farrokhyar F, Sivakumar G, Savage K, Koziarz A, Jamshidi S, Ayeni OR, et al. Effects of vitamin d supplementation on serum 25 -hydroxyvitamin d concentrations and physical performance in athletes: A systematic review and meta-analysis of randomized controlled trials. Sports Med. 2017 Nov;47(11):2323-39.

49 Christakos S, Dhawan P, Verstuyf A, Verlinden L, Carmeliet G. Vitamin D: metabolism, molecular mechanism of action, and pleiotropic effects. Physiol Rev. 2016 Jan;96(1):365408.

50 Hales CM, Fryar CD, Carroll MD, Freedman DS, Ogden CL. Trends in obesity and severe obesity prevalence in us youth and adults by sex and age, 2007-2008 to 2015-2016. JAMA. 2018 Apr;319(16):1723-5.

51 Zhang L, Wang Z, Wang X, Chen Z, Shao L, Tian Y, et al.; China Hypertension Survey investigators. Prevalence of abdominal obesity in China: results from a cross-sectional study of nearly half a million participants. Obesity (Silver Spring). 2019 Nov;27(11):1898-905.

52 Chan JC, Malik V, Jia W, Kadowaki T, Yajnik CS, Yoon KH, et al. Diabetes in Asia: epidemiology, risk factors, and pathophysiology. JAMA. 2009 May;301(20):2129-40.

53 Fan JG, Kim SU, Wong VW. New trends on obesity and NAFLD in Asia. J Hepatol. 2017 Oct;67(4):862-73.

54 Padwal R, Li SK, Lau DC. Long-term pharmacotherapy for obesity and overweight. CochraneDatabaseSystRev.2003;(4):CD004094. 